\title{
Florística e estrutura da comunidade arbórea de um remanescente de Floresta Estacional Decidual de encosta, Monte Alegre, GO, Brasil
}

\author{
André R. Terra Nascimento ${ }^{1}$, Jeanine Maria Felfili ${ }^{2,3}$ e Elisa Maria Meirelles ${ }^{2}$
}

Recebido em 27/05/2002. Aceito em 23/02/2004

\begin{abstract}
RESUMO - (Florística e estrutura da comunidade arbórea de um remanescente de Floresta Estacional Decidual de encosta, Monte Alegre, GO, Brasil). O presente estudo teve como objetivo descrever a composição de espécies arbóreas e a estrutura de um fragmento de Floresta Estacional Decidual, na região Nordeste de Goiás, Brasil. Foram levantadas 25 unidades amostrais quadradas de 20×20m, totalizando uma amostra de um hectare, sendo incluídos na amostragem todos os indivíduos com diâmetros iguais ou superiores a $5 \mathrm{~cm}$. Foram amostrados 663 indivíduos pertencentes a 52 espécies arbóreas, destacando-se pela densidade as espécies Combretum duarteanum Camb., Casearia rupestris Eichl., Myracrodruon urundeuva Fr. Allem., Machaerium acutifolium Vog. e Tabebuia impetiginosa (Mart. ex DC.) Standl. Foram encontradas 21 famílias botânicas, com maior representatividade da família Leguminosae (17 espécies) e das famílias Bignoniaceae (4 espécies), Anacardiaceae ( 3 espécies) e Bombacaceae (3 espécies). A vegetação estudada apresentou dossel descontínuo e distribuição diamétrica desequilibrada, com valores do quociente de Liocourt "q" variando de q1=0,66 a q6 $=0,14$. Estes remanescentes florestais desempenham papel importante na manutenção da diversidade biológica e possuem espécies arbóreas madeiráveis de importância econômica, que se tornaram raras em outros locais da região Nordeste de Goiás.
\end{abstract}

Palavras-chave: florestas decíduas, fitossociologia, árvores

\begin{abstract}
Floristic and structure of a seasonal deciduous forest fragment, Monte Alegre, GO, Brazil). The objective of this study was to describe the floristic composition and the structure of the tree layer of a fragment of a seasonal deciduous forest in northeastern Goiás state, Brazil. A sample of $25(20 \times 20)$ plots was assessed totaling one hectare. All individuals for $5 \mathrm{~cm}$ dbh were included in the survey. A total of 663 trees in 52 arboreal species was found; the most abundant species were Combretum duarteanum Camb., Casearia rupestris Eichl., Myracrodruon urundeuva Fr. Allem., Machaerium acutifolium Vog. and Tabebuia impetiginosa (Mart. ex DC.) Standl. There were 21 families with a higher proportion of Leguminosae (17 species) Bignoniaceae (4 species), Anacardiaceae ( 3 species) and Bombacaceae ( 3 species). The forest presented an open canopy and an unbalanced diameter distribution, with Liocourt's quocient "q" values ranging from $\mathrm{q} 1=0,66$ to $\mathrm{q} 6=0.14$. These forest remnants play an important role in the maintenance of the biological diversity and contain valuable timber species that are becoming rare in the surrounding regions.
\end{abstract}

Key words: deciduous forests, phytosociology, trees

\section{Introdução}

As Florestas Estacionais Deciduais de Encosta, também conhecidas como 'Matas Secas de Calcário' são formações vegetais que ocorrem em áreas de afloramento de calcário no bioma Cerrado. Estas florestas naturais apresentam estratificação desenvolvida e espécies arbóreas de maiores dimensões (altura total e forma do fuste) que a vegetação de cerrado nas suas distintas fitofisionomias.

A designação de Mata Seca é aplicada para as formações florestais caracterizadas por diversos níveis de caducifolia durante a estação seca, dependentes das condições químicas, físicas e, principalmente, da profundidade do solo. A mata seca não possui associação com cursos de água, ocorrendo nos interflúvios em solos mais ricos em nutrientes. A mata seca decídua pode apresentar-se com aspecto singular (estrutura e ambiente) se ocupar áreas rochosas de origem calcária, quando também é conhecida como "Mata Seca em solo Calcário" ou ainda "Mata Calcária". Tais áreas em geral são bastante acidentadas e possuem composição florística ligeiramente diferenciada dos demais tipos de mata seca (Ribeiro $\&$ Walter 1998).

As matas mesofíticas (florestas estacionais) apresentam cobertura arbórea de 70 a $90 \%$ na estação chuvosa. A maioria das espécies é caducifólia na

\footnotetext{
1 Instituto de Biociências, Universidade de Brasília, Departamento de Engenharia Florestal, C. Postal 04357, CEP 70910-900, Brasília, DF, Brasil (arterra@unb.br)

2 Departamento de Engenharia Florestal, Faculdade de Tecnologia, UnB

3 Autor para correspondência: felfili@unb.br
} 
estação seca, quando a cobertura arbórea atinge níveis inferiores a 50\%. Os fustes das árvores são retilíneos, sendo comum a presença de indivíduos emergentes do dossel que atingem alturas de 20-30m. Epífitas em geral são pouco abundantes, porém Bromeliáceas e Cactáceas são freqüentes, pois a baixa fertilidade e a baixa disponibilidade de água no solo favorecem espécies destas famílias (Felfili 2001).

Para as florestas secas sob afloramento de calcário em Minas Gerais, Pedralli (1997) descreveu um estrato arbóreo com dossel descontínuo, e onde a floresta apresenta dossel, este se apresenta com maior adensamento, podendo-se observar também a ocorrência de clareiras naturais. Os indivíduos que se sobressaem (emergentes), podem atingir alturas de $20 \mathrm{~m}$. Neste estrato ocorrem Anadenanthera colubrina (angico), Myracrodruon urundeuva (aroeira), Phytolacca dioica (cebolão), Celtis iguanea (esporão-de-galo), Cedrela odorata (cedro), Enterolobium contortisiliquum (tamboril), dentre outras espécies.

Aspecto importante da maior parte das florestas tropicais é o expressivo número de espécies vegetais com baixas densidades por hectare (Hartshorn 1980; Hubbell \& Foster 1985; 1987; Carvalho 1992; Martijena \& Bullock 1994; Felfili 1995; Finegan 1996; Miller \& Kauffman 1998). Este padrão também é descrito para florestas deciduais na Costa Rica (Hubbell 1979) e Bolívia (Pinard 1999). Estas observações apresentam caráter importante quando se consideram aspectos de manejo e de conservação destas comunidades vegetais, denotando distintas práticas silviculturais para espécies com baixa densidade de indivíduos, em comparação com as espécies que apresentam densidade elevada na vegetação.

O principal fator que controla a vegetação terrestre tropical é a severidade da estação seca. A mudança climática das áreas de florestas muito úmidas para áreas áridas desérticas é gradual, sendo o limite entre as fisionomias de floresta e savana bastante abrupto (Hopkins 1992). Em um fragmento de Floresta Estacional Decidual no Vale do Paranã, Sampaio (2001) descreveu que o efeito de borda é menos evidente nestas florestas que em florestas Tropicais úmidas e Temperadas, possivelmente, devido às características estruturais distintas das florestas Estacionais. Estudando uma Floresta Estacional semidecídua e monodominante no Mato Grosso, Felfili et al. (1998) descrevem distribuição diamétrica com tendência clara ao J-invertido, com uma razão "q" inconstante, indicando que naquela floresta não está havendo balanço entre a mortalidade e o recrutamento para as distintas classes de diâmetro da comunidade vegetal. As árvores apresentaram diâmetros máximos de $65 \mathrm{~cm}$ e com a maioria dos indivíduos com diâmetros menores que $45 \mathrm{~cm}$. A espécie de maior densidade (Brosimun rubescens Taub.) apresentou distribuição diamétrica irregular, com poucos indivíduos nas menores classes de diâmetro.

Pouco se sabe sobre as Florestas Estacionais do Brasil Central, mas é evidente que elas estão sendo rapidamente convertidas em paisagens agrícolas, especialmente em pastagens. Este estudo teve como objetivo descrever a composição de espécies e a estrutura do componente arbóreo de um remanescente de Floresta Estacional Decidual e discutir aspectos para a conservação e o manejo de Florestas Estacionais sobre afloramento de calcário na região Nordeste de Goiás.

\section{Material e métodos}

Área de estudo - O presente trabalho foi desenvolvido em um remanescente de Floresta Estacional Decidual de 70ha, localizado no município de Monte Alegre, região Nordeste do Estado de Goiás, entre as coordenadas geográficas de $13^{\circ} 08^{\prime} 50^{\prime \prime} \mathrm{S}$ e 46039'34'W. Esta região compreende o denominado Vale do Paranã, que foi incluído na Reserva de Biosfera do Cerrado Fase 2 e também é considerado como corredor ecológico prioritário para conservação do Cerrado e das Florestas Estacionais pelo IBAMA.

Esta região apresenta um mosaico de vegetação de Cerrado, Florestas Decíduas e Florestas Semidecíduas (IBGE 1990). Nos locais de declividade acentuada e com presença de afloramento de calcário ocorre a Floresta Estacional Decidual de Encosta (Fig. 1). As Florestas Estacionais deciduais ocorrem em áreas disjuntas dos Neotrópicos e possuem maior deciduidade dos elementos arbóreos durante a estação seca. Espécies com flores conspícuas e sementes dispersas pelo vento são freqüentes, em contraste com as florestas tropicais úmidas, e a cobertura ao nível do solo é esparsa, consistindo de poucas gramíneas, e espécies de Bromeliaceae, Compositae, Malvaceae e Marantaceae (Pennington et al. 2000).

A temperatura média anual está situada em torno de $23,3^{\circ} \mathrm{C}$, variando de $21,7^{\circ} \mathrm{C}$ no mês mais frio (junho) e $24,7^{\circ} \mathrm{C}$ no mês mais quente (setembro). A precipitação total anual $(\mathrm{mm})$ é $1537,5 \mathrm{~mm}$ oscilando de $4,9 \mathrm{~mm}$ no mês mais seco (julho) a $280 \mathrm{~mm}$ no mês mais chuvoso (dezembro) (dados do município de Posse, única estação climatológica da região, DNMET 1992). 


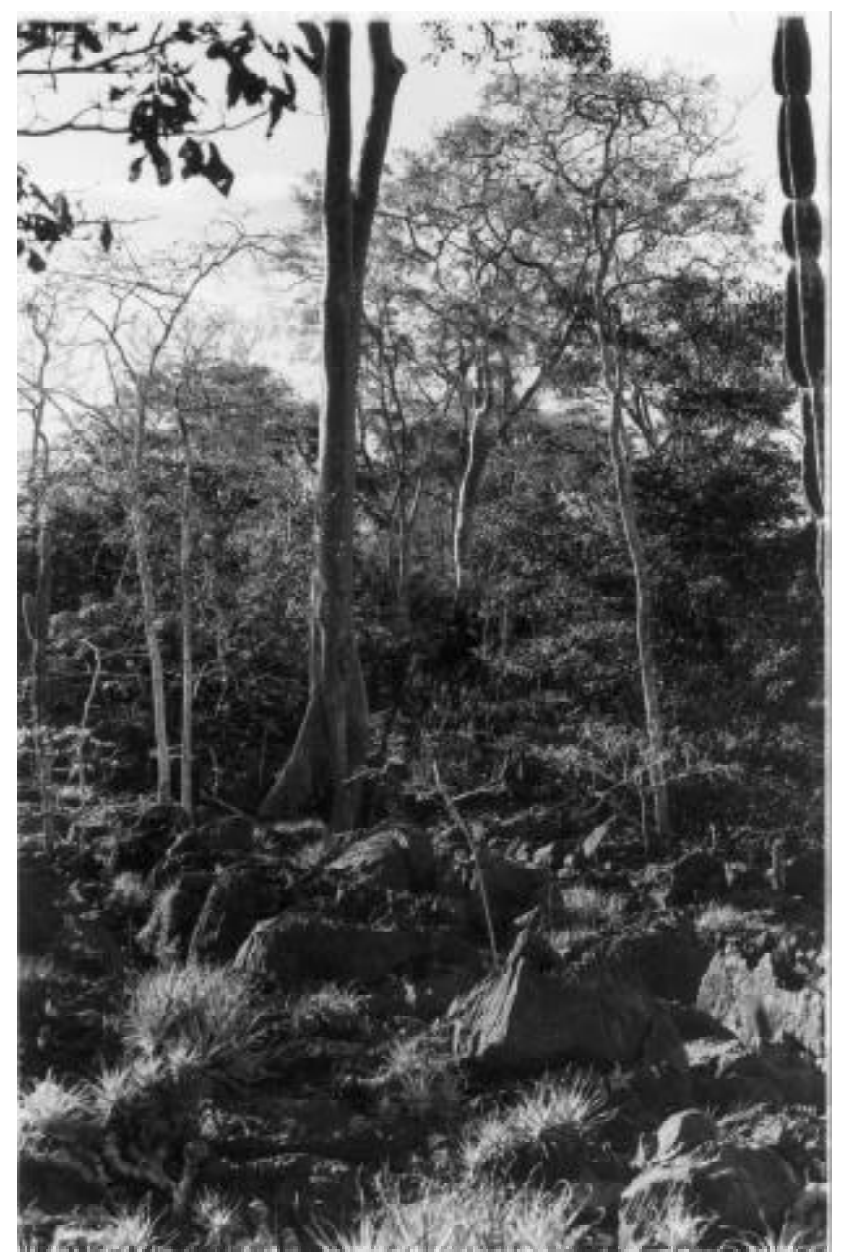

Figura 1. Aspecto da Floresta Estacional Decidual de Encosta sob afloramento de calcário na região Nordeste de Goiás, Brasil. Notar a deciduidade dos elementos arbóreos que formam o dossel (estação seca) e a presença de afloramento de calcário no solo da floresta.

A hipsometria revela altitudes em torno de 200-500m, e o relevo apresenta-se suaveondulado (3-8\% de declividade), com trechos mais acidentados e relevo ondulado (13-20\% de declividade) nas áreas de encosta dos morros (FINATEC 2001).

A geologia destaca unidades oriundas do Meso/ neoproterozóico, pertencendo ao grupo Paranoá (unidade Mpa2), que é composta de metassiltitos argilosos esverdeados homogêneos, com intercalações arenosas compondo metarritmitos e lentes de calcário e dolomitos, e no topo, metarritmito palítico a arenosos contendo bancos decimétricos de quartzitos e metassiltitos que gradam para ardósias homogêneas de cor cinza esverdeada, que passa a cor vermelha característica com a alteração intempérica. Predominam na área os seguintes tipos de solo: Plintossolos (derivados de lateritas hidromórficas), Latossolo Vermelho Escuro álico (Lea) e Cambissolo Litólico álico (Cla) (FINATEC 2001).
Nas Florestas decíduas onde o material é proveniente do calcário, normalmente as rochas são pouco resistentes ao intemperismo, permitindo, entretanto, que elementos trocáveis (como o cálcio e magnésio) ainda estejam presentes no solo. No Brasil Central, os solos mais jovens são encontrados em relevos mais acidentados, sendo normalmente ricos em bases. Os solos mais antigos, que ocupam posições mais aplainadas da paisagem, normalmente são de fertilidade baixa, pois são solos mais intemperizados, profundos, e dessa forma, a maior parte do cálcio e do magnésio já saiu do sistema (Reatto et al. 1998).

Amostragem - O fragmento de 70ha foi dividido em faixas de $20 \mathrm{~m}$ de largura perpendiculares ao gradiente longitudinal como sugerido por Felfili (1995) para áreas florestais de pequena dimensão e submetidas a forte gradiente ambiental. Neste caso, o gradiente principal é a encosta. Em seguida, essas faixas foram subdivididas em parcelas de $20 \times 20 \mathrm{~m}\left(400 \mathrm{~m}^{2}\right)$ e procedeu-se ao sorteio de 25 parcelas, de modo que a amostra totalizou um hectare. Em cada unidade amostral foram mensuradas todas as árvores com $\mathrm{DAP} \geq 5 \mathrm{~cm}(\mathrm{CAP}=15,78 \mathrm{~cm})$. Cada indivíduo incluído na amostragem foi marcado com plaquetas de alumínio numeradas e teve a sua circunferência à altura do peito (CAP) e a altura total mensuradas.

As espécies foram identificadas no campo e foi coletado material testemunho (exsicatas) durante várias excursões de coleta, realizadas tanto na estação seca como na chuvosa para obtenção de espécimes férteis. $\mathrm{O}$ material testemunho encontra-se depositado no Herbário do IBGE em Brasília, DF.

Os parâmetros fitossociológicos (densidade, freqüência e dominância absolutas e relativas e valor de importância) foram obtidos com o uso do Software INFLO I, desenvolvido no Centro de Processamento de Dados da Universidade de Brasília.

Os diâmetros dos indivíduos marcados foram distribuídos em classes com intervalos de $5 \mathrm{~cm}$ determinados com base na fórmula de Spiegel (1976), também com o uso da programa INFLO I. Foi calculado o Quociente "q" de Liocourt. Este quociente é obtido dividindo cada classe diamétrica pela anterior, e permite fazer inferências sobre o recrutamento e a mortalidade em florestas naturais. Uma razão constante entre as classes indica que a taxa de recrutamento é similar à taxa de mortalidade e a distribuição pode ser considerada regular ou equilibrada.

Para as seis espécies arbóreas mais importantes (sendo três delas espécies de importância econômica) 
foram representadas as suas distribuições diamétricas, com classes de intervalo de $10 \mathrm{~cm}$.

\section{Resultados e discussão}

Composição florística - O fragmento estudado apresentou 52 espécies arbóreas com DAP $\geq 5 \mathrm{~cm}$. Os gêneros Machaerium (3 espécies), Aspidosperma (3 espécies), Tabebuia (3 espécies) e Anadenanthera (3 espécies) foram os mais bem representados na composição de espécies nesta comunidade vegetal (Tab. 1).

Foram amostrados no hectare o total de 663 indivíduos, destacando-se, pela densidade, as espécies Combretum duarteanum, Casearia rupestris,
Myracrodruon urundeuva, Tabebuia roseoalba, Dilodendron bipinnatum e Pseudobombax tomentosum. O dossel da floresta é aberto, com trechos onde as copas não se tocam e com maior insolação atingindo o solo, e trechos com maior cobertura vegetal representada pelos diferentes estratos da floresta.

As espécies Combretum duarteanum, Myracrodruon urundeuva, Pseudobombax tomentosum, Casearia rupestris, Dilodendron bipinnatum, Tabebuia roseoalba, Tabebuia impetiginosa e Cavanillesia arborea são as espécies que se destacam na comunidade, considerando o valor de importância, representando estas oito espécies cerca de $51 \%$ do total para o componente arbóreo.

Tabela 1. Espécies arbóreas e seus parâmetros fitossociológicos organizadas em ordem decrescente de VI, amostrada. H max. - Altura máxima; Ds. Ab. - Densidade Absoluta, Ds. Rel. - Densidade Relativa; Fr. Abs. - Freqüência Absoluta, Fr. Rel. - Freqüência Relativa; Do. Abs. - Dominância Absoluta, Do. Rel. - Dominância Relativa; VI - Valor de Importância na Floresta Estacional Decidual em Monte Alegre, Goiás, Brasil.

\begin{tabular}{|c|c|c|c|c|c|c|c|c|}
\hline Espécie & $\begin{array}{l}\mathrm{H} \max . \\
(\mathrm{m})\end{array}$ & $\begin{array}{r}\text { Ds. Ab. } \\
\text { (n/ha) }\end{array}$ & $\begin{array}{c}\text { Ds. Rel. } \\
(\%)\end{array}$ & $\begin{array}{l}\text { Do. Abs. } \\
\left(\mathrm{m} 2 \cdot \mathrm{ha}^{-1}\right)\end{array}$ & $\begin{array}{c}\text { Do. Rel. } \\
\text { (\%) }\end{array}$ & $\begin{array}{c}\text { Fr. Abs. } \\
(\%)\end{array}$ & $\begin{array}{c}\text { Fr. Rel. } \\
(\%)\end{array}$ & VI \\
\hline Combretum duarteanum & 11 & 127,89 & 19,3 & 1,0804 & 5,08 & 62 & 5,63 & 29,79 \\
\hline Myracrodruon urundeuva & 22 & 48,08 & 7,26 & 2,3210 & 11,97 & 62 & 5,63 & 24,80 \\
\hline Pseudobombax tomentosum & 14 & 30,77 & 4,64 & 2,5323 & 13,06 & 62 & 5,63 & 23,27 \\
\hline Casearia rupestris & 8 & 73,08 & 11,03 & 0,6014 & 3,10 & 54 & 4,93 & 19,00 \\
\hline Dilodendron bipinnatum & 13 & 34,62 & 5,22 & 1,0531 & 5,43 & 58 & 5,28 & 15,87 \\
\hline Tabebuia roseoalba & 8 & 42,31 & 6,39 & 0,4754 & 2,45 & 62 & 5,63 & 14,40 \\
\hline Tabebuia impetiginosa & 22 & 18,27 & 2,76 & 1,2480 & 6,43 & 54 & 4,93 & 14,06 \\
\hline Mortas & - & 26,92 & 4,06 & 0,6412 & 3,31 & 54 & 4,93 & 11,52 \\
\hline Cavanillesia arborea & 23 & 1,92 & 0,29 & 2,1629 & 11,15 & 8 & 0,69 & 12,15 \\
\hline Machaerium acutifolium & 21 & 24,04 & 3,63 & 0,9833 & 5,07 & 35 & 3,13 & 11,83 \\
\hline Astronium fraxinifolium & 25 & 21,15 & 3,19 & 0,7543 & 3,89 & 50 & 4,51 & 11,60 \\
\hline Guazuma ulmifolia & 8 & 17,31 & 2,61 & 0,2828 & 1,46 & 50 & 4,51 & 8,59 \\
\hline Rhamnidium elaeocarpum & 9 & 23,08 & 3,48 & 0,2426 & 1,25 & 42 & 3,47 & 7,49 \\
\hline Aspidosperma subincanum & 16 & 14,42 & 2,18 & 0,5048 & 2,60 & 38 & 3,47 & 8,26 \\
\hline Lonchocarpus montanus & 12 & 20,19 & 3,05 & 0,3107 & 1,60 & 27 & 0,35 & 1,17 \\
\hline Sterculia striata & 15 & 10,58 & 1,60 & 0,3854 & 1,99 & 35 & 3,13 & 6,57 \\
\hline Machaerium scleroxylon & 15 & 9,62 & 1,45 & 0,6182 & 3,19 & 19 & 1,74 & 4,90 \\
\hline Aspidosperma pyrifolium & 14 & 12,50 & 1,89 & 0,1987 & 1,02 & 31 & 2,78 & 5,69 \\
\hline Spondias mombin & 22 & 5,77 & 0,87 & 0,5819 & 3,00 & 19 & 1,74 & 5,61 \\
\hline Ximenia americana & 9 & 12,50 & 1,89 & 0,3679 & 1,90 & 19 & 1,74 & 5,52 \\
\hline Anadenanthera peregrina & 13 & 13,46 & 2,03 & 0,2017 & 1,04 & 23 & 2,08 & 4,61 \\
\hline Erythrina verna & 10 & 4,81 & 0,73 & 0,1959 & 1,01 & 19 & 1,39 & 2,40 \\
\hline Jacaranda brasiliana & 14 & 5,77 & 0,87 & 0,1731 & 0,89 & 15 & 1,39 & 3,15 \\
\hline Guettarda viburnoides & 8 & 6,73 & 1,02 & 0,0557 & 0,29 & 19 & 1,74 & 3,04 \\
\hline Oxandra reticulata & 13 & 5,77 & 0,87 & 0,2389 & 1,23 & 8 & 0,69 & 2,80 \\
\hline Machaerium stipitatum & 13 & 2,89 & 0,44 & 0,1076 & 0,56 & 12 & 1,04 & 2,03 \\
\hline Callisthene fasciculata & 16 & 2,89 & 0,44 & 0,1046 & 0,54 & 12 & 1,04 & 2,02 \\
\hline Campomanesia xanthocarpa & 3,5 & 4,81 & 0,73 & 0,0182 & 0,09 & 12 & 1,04 & 1,86 \\
\hline Tocoyena formosa & 8 & 3,85 & 0,58 & 0,0229 & 0,12 & 12 & 1,04 & 1,74 \\
\hline Zanthoxylum riedelianun & 13 & 1,92 & 0,29 & 0,0743 & 0,38 & 8 & 0,69 & 1,37 \\
\hline Bauhinia membranacea & 8 & 2,89 & 0,44 & 0,0415 & 0,21 & 8 & 0,69 & 1,34 \\
\hline Maclura tinctoria & 10 & 2,89 & 0,44 & 0,0352 & 0,18 & 8 & 0,69 & 1,31 \\
\hline Swartzia multijuga & 11 & 1,92 & 0,29 & 0,0564 & 0,29 & 8 & 0,69 & 1,28 \\
\hline
\end{tabular}


Tabela 1 (continuação)

\begin{tabular}{|c|c|c|c|c|c|c|c|c|}
\hline Espécie & $\begin{array}{l}\mathrm{H} \max . \\
(\mathrm{m})\end{array}$ & $\begin{array}{c}\text { Ds. Ab. } \\
\text { (n/ha) }\end{array}$ & $\begin{array}{l}\text { Ds. Rel. } \\
(\%)\end{array}$ & $\begin{array}{l}\text { Do. Abs. } \\
\left(\mathrm{m} 2 \cdot \mathrm{ha}^{-1}\right)\end{array}$ & $\begin{array}{l}\text { Do Rel. } \\
\qquad(\%)\end{array}$ & $\begin{array}{c}\text { Fr. Abs. } \\
(\%)\end{array}$ & $\begin{array}{c}\text { Fr. Rel. } \\
(\%)\end{array}$ & VI \\
\hline Anadenanthera colubrina & 8 & 1,92 & 0,29 & 0,0536 & 0,28 & 8 & 0,69 & 1,26 \\
\hline Acacia paniculata & 6 & 2,89 & 0,44 & 0,0231 & 0,12 & 8 & 0,69 & 1,25 \\
\hline Enterolobium contortisiliquum & 13 & 0,96 & 0,15 & 0,1415 & 0,73 & 4 & 0,35 & 1,22 \\
\hline Samanea tubulosa & 13 & 0,96 & 0,15 & 0,1253 & 0,65 & 4 & 0,69 & 1,14 \\
\hline Triplaris gardneriana & 6 & 1,92 & 0,29 & 0,0179 & 0,09 & 8 & 0,35 & 1,08 \\
\hline Casearia grandiflora & 12 & 0,96 & 0,15 & 0,0811 & 0,42 & 4 & 0,35 & 0,91 \\
\hline Alibertia macrophylla & 4 & 2,89 & 0,44 & 0,0216 & 0,11 & 4 & 0,35 & 0,89 \\
\hline Psidium sartorianum & 10 & 0,96 & 0,15 & 0,0734 & 0,38 & 4 & 0,69 & 1,94 \\
\hline Chloroleucon tenuiflorum & 8 & 0,96 & 0,15 & 0,0539 & 0,28 & 4 & 0,35 & 0,77 \\
\hline Acacia polyphylla & 5 & 1,92 & 0,29 & 0,0174 & 0,09 & 4 & 0,35 & 0,73 \\
\hline Anadenanthera macrocarpa & 4 & 0,96 & 0,15 & 0,0396 & 0,20 & 4 & 0,35 & 0,70 \\
\hline Piptadenia gonoacantha & 8 & 0,96 & 0,15 & 0,0257 & 0,13 & 4 & 0,35 & 0,63 \\
\hline Eriotheca gracilipes & 6 & 0,96 & 0,15 & 0,0141 & 0,07 & 4 & 0,35 & 0,57 \\
\hline Talisia esculenta & 6 & 0,96 & 0,15 & 0,0064 & 0,03 & 4 & 0,35 & 0,53 \\
\hline Guapira paraguayensis & 4 & 0,96 & 0,15 & 0,0051 & 0,03 & 4 & 0,35 & 0,52 \\
\hline Cordia trichotoma & 6 & 0,96 & 0,15 & 0,0044 & 0,02 & 4 & 0,35 & 0,52 \\
\hline Combretum sp. & 7 & 0,96 & 0,15 & 0,0044 & 0,02 & 4 & 0,69 & 1,19 \\
\hline Platypodium elegans & 4 & 0,96 & 0,15 & 0,0044 & 0,02 & 4 & 0,35 & 0,52 \\
\hline Tabebuia serratifolia & 3,5 & 0,96 & 0,15 & 0,0030 & 0,02 & 4 & 0,35 & 0,51 \\
\hline Aspidosperma sp. & 3 & 0,96 & 0,15 & 0,0027 & 0,01 & 4 & 0,35 & 0,51 \\
\hline Total & & 662,51 & 100,0 & 19,3694 & 100,0 & 1108 & 100,0 & 300,0 \\
\hline
\end{tabular}

As árvores com os maiores diâmetros na amostragem foram Cavanillesia arborea $(\mathrm{DAP}=135,5 \mathrm{~cm})$ e Myracrodruon urundeuva $(\mathrm{DAP}=44,6 \mathrm{~cm})$. A espécie Combretum duarteanum apresentou o maior valor de importância da comunidade devido aos elevados valores de densidade e freqüência por hectare, mesmo apresentando indivíduos de porte mediano, com menores valores de dominância na vegetação.

Em fragmentos de Floresta Estacional Decidual, em terreno plano, nesta mesma região do Vale do Paranã, Scariot e Sevilha (2000) descreveram riqueza ligeiramente inferior com 44 a 48 espécies arbóreas acima de $5 \mathrm{~cm}$ diâmetro e um índice de Shannon (H') de 2,98 a 3,03 para três fragmentos de Floresta Estacional localizados na região Nordeste do Estado de Goiás.

Foram encontradas 21 famílias botânicas, com uma maior riqueza de espécies na família Leguminosae (30,7\% do total) (Fig. 2). As famílias Bignoniaceae (4 espécies), Anacardiaceae (3 espécies) e Bombacaceae (3 espécies) vêm logo a seguir $(5,77 \%$ do total), no entanto, com uma menor representatividade de espécies.

A proporção de espécies por gênero foi maior para as famílias as Bignoniaceae (2:1), Leguminosae $(1,41: 1)$, que foram as famílias com maior riqueza de espécies (Tab. 3). As famílias Apocynaceae (1:1), Anacardiaceae (1:1), Rubiaceae (1:1) e Bombacaceae (1:1) apresentaram uma espécie por gênero, mas contribuem com três espécies cada uma, estando em segundo e terceiro lugares em número de espécies. Do total das famílias encontradas $(n=21)$, proporção expressiva $(45 \%)$ apresentou somente uma espécie incluída na amostragem.

Esta grande representatividade de espécies das famílias Leguminosae e Bignoniaceae é reportada como um importante padrão fitogeográfico para Florestas Estacionais Deciduais (Gentry 1995;

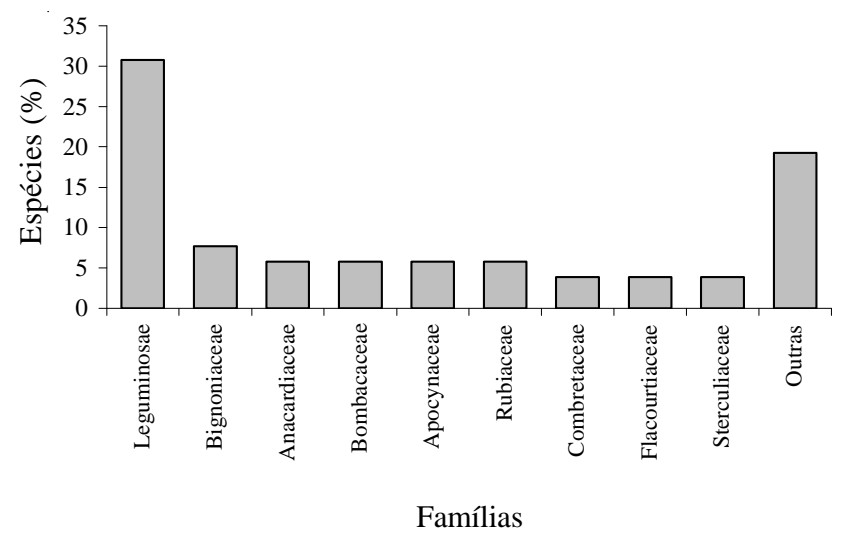

Figura 2. Percentagem do número de espécies por família botânica na Floresta Estacional Decidual em Monte Alegre, Goiás, Brasil. 
Pennington et al. 2000). As outras famílias somam o total de 12 e estão representadas por poucas espécies e, na maior parte dos casos, por somente uma única espécie, contribuindo de forma menos significativa na riqueza de espécies da comunidade.

Para uma Floresta Decídua em Minas Gerais, Rodrigues \& Araújo (1997) descreveram diversidade arbórea de 69 espécies, com predomínio de Anadenanthera colubrina, Myracrodroun urundeuva e Sweetia fruticosa. As famílias com maior número de espécies foram Euphorbiaceae (10 espécies), Rubiaceae (8 espécies), Mimosaceae (6 espécies) e Myrtaceae (6 espécies). Considerando Leguminosae como uma única família são enumeradas 16 espécies e corresponde a cerca de $23,2 \%$ do total. As espécies Acacia polyphylla (Mimosaceae), Anadenanthera colubrina (Mimosaceae) e Machaerium brasiliense (Fabaceae) perfizeram 36,3\% do Valor de Importância em outra Floresta Estacional Decidual em Minas Gerais (Oliveira-Filho et al. 1998).

As árvores mortas (26 indivíduos com DAP $\geq 5 \mathrm{~cm}$ ) representam cerca de $4 \%$ do total do número de indivíduos. Este valor é inferior ao valor de $5,3 \%$ encontrado por Vaccaro (1997), para uma Floresta Estacional Decidual no Sul do Brasil, e de 7,4\%, encontrado por Martins (1991) para uma floresta Mesófila no Estado de São Paulo, mas está na faixa encontrada para Florestas de Galeria (Felfili 1995) e Cerrados não perturbados (Felfili et al. 2001; Felfili et al. 2002).

Estrutura da vegetação - A altura das espécies variou de 2,5m para indivíduos do sub-bosque, até valores de $25 \mathrm{~m}$ para as espécies emergentes do dossel, como Astronium fraxinifolium $(25 \mathrm{~m})$ e Cavanillesia arborea $(23 \mathrm{~m})$, que foram as maiores árvores encontradas na amostragem da vegetação. A maior parte dos indivíduos atinge até cerca de $12 \mathrm{~m}$ (Fig. 3). Os indivíduos com menores alturas pertencem às espécies Combretum duarteanum (2,5m) e Alibertia edulis $(3,0 \mathrm{~m})$, que são de porte intermediário.

As espécies arbóreas decíduas muitas vezes constituem a forma de vida predominante nas fisionomias florestais deciduais. A proporção de árvores decíduas aumenta das formações florestais úmidas (disponibilidade hídrica influenciada pelas chuvas orográficas) paras as florestas deciduais com cobertura relativa menor que $50 \%$. As espécies arbóreas decíduas e as espécies de Cactáceas e de caules suculentos apresentam aumento em relação ao gradiente de redução da disponibilidade de água entre as distintas

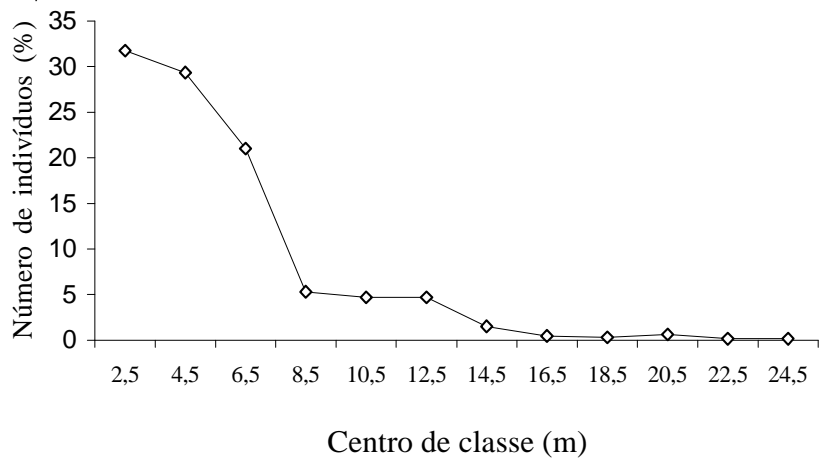

Figura 3. Distribuição das alturas dos indivíduos amostrados em um remanescente de Floresta Estacional Decidual, Monte Alegre, Goiás, Brasil.

comunidades das florestas deciduais neotropicais (Medina 1995).

As estimativas da riqueza de espécies e da densidade estão dentro dos valores encontrados para florestas estacionais em diferentes locais (Tab. 2). Os valores de área basal (representados pela dominância dos fustes por hectare), embora ligeiramente inferiores aos encontrados para outras amostragens, juntamente com a riqueza de espécies por hectare, podem ser considerados dentro dos padrões para este tipo de vegetação

Esses remanescentes de Floresta Estacional Decidual encontram-se em locais de declividade acentuada e são utilizados pela agricultura e desempenham importante papel na manutenção deste tipo de vegetação na região do Vale do Paranã. Para as florestas estacionais deciduais do México, Trejo \& Dirzo (2000) destacaram que a proporção de remanescentes florestais intactos incrementa com a declividade, atingindo valores maiores que $40 \%$ nos trechos com declividade $\geq 45^{\circ}$. No entanto, as elevadas taxas de desflorestamento (1,4\% ao ano), demonstram que, embora ainda exista cerca de $27 \%$ da cobertura original desta formação florestal, somente $7,5 \%$ da área total compreende florestas intactas ou pouco alteradas.

As espécies que somam a maior parte da área basal são Pseudobombax tomentosum $\left(2,53 \mathrm{~m}^{2} / \mathrm{ha}\right)$, Myracrodruon urundeuva $\left(2,32 \mathrm{~m}^{2} / \mathrm{ha}\right)$, Cavanillesia arborea $\left(2,16 \mathrm{~m}^{2} / \mathrm{ha}\right)$, Tabebuia impetiginosa $\left(1,24 \mathrm{~m}^{2} / \mathrm{ha}\right)$ e Dilodendron bipinnatum $\left(1,05 \mathrm{~m}^{2} / \mathrm{ha}\right)$ representando estas cinco espécies cerca de $48 \%$ da área basal total do hectare $\left(19,36 \mathrm{~m}^{2}\right)$ (Tab. 1). Destas espécies, somente Cavanillesia arborea apresenta baixos valores de densidade e está bem representada entre as primeiras devido ao grande porte e dimensões dos fustes dos seus indivíduos. 
Tabela 2. Estimativas de Riqueza, Densidade e Área Basal por hectare para Florestas Estacionais em diferentes locais.

\begin{tabular}{|c|c|c|c|c|c|}
\hline Tipo de Floresta & $\begin{array}{c}\text { Diâmetro } \\
\text { mínimo }(\mathrm{cm})\end{array}$ & N. espécies & $\begin{array}{l}\text { Dens. } \\
\text { (ha) }\end{array}$ & $\begin{array}{c}\mathrm{G} \\
\left(\mathrm{m}^{2} / \mathrm{ha}\right)\end{array}$ & Fonte \\
\hline Estacional Decidual & 5 & 52 & 633,0 & 19,36 & Este estudo \\
\hline Estacional Decidual & 5 & 72 & 510,0 & 20,00 & Felfili et al. $(1998)^{1}$ \\
\hline Estacional Decidual & 5 & 48 & 674,0 & 24,54 & Scariot \& Sevilha $(2000)^{2}$ \\
\hline Estacional Decidual & 5 & 44 & 591,0 & 23,17 & Scariot \& Sevilha $(2000)^{2}$ \\
\hline Estacional Decidual & 1 & 72 & 518,0 & 25,92 & Sukumar et al. $(1998)^{3}$ \\
\hline Estacional Decidual & 5 & 60 & 1378,0 & 45,92 & Oliveira-Filho et al. $(1998)^{4}$ \\
\hline Caducifólia Espinhosa (Caatinga) & 3 & 56 & 5827,0 & 31,90 & Jesus \& Rodal $(2002)^{5}$ \\
\hline Estacional Semidecidual & 5 & 67 & 1454,0 & 20,54 & Oliveira-Filho et al. $(1997)^{6}$ \\
\hline
\end{tabular}

Dens - densidade absoluta/ha; G - área basal por hectare $\left(\mathrm{m}^{2}\right)$. ${ }^{1}$ Floresta em Nova Xavantina, MS; ${ }^{2}$ Florestas em São Domingos, GO; ${ }^{3}$ Floresta em Mudumalai, Índia; ${ }^{4}$ Floresta em Lavras, MG; ${ }^{5}$ Floresta em São Raimundo Nonato, PI; ${ }^{6}$ Floresta em Santa Vitória, MG.

Distribuição diamétrica da floresta e das principais espécies - A comunidade vegetal apresentou distribuição das classes de diâmetro tendendo ao J-invertido (Fig. 4), com os valores calculados para o Quociente de Liocourt “q" variando de $\mathrm{q} 1=0,66$ a $\mathrm{q} 6=0,14$, estando a maior parte dos valores entre 0,32 e 0,66. O padrão de J-invertido é também descrito para Florestas de Galeria no Brasil Central (Felfili 1995; 1997; Silva Junior 1995), para Florestas Estacionais no Sul do Brasil (Vaccaro 1997) e também para uma floresta monodominante de Brosimum rubescens Taub. (Marimon et al. 2001) no Mato Grosso, além de várias outras formações tropicais.

Distribuições diamétricas equilibradas, nas quais o recrutamento compensa a mortalidade ao longo do tempo (Felfili 1997), apresentam valores relativamente constantes de "q" entre as classes de diâmetro (Meyer et al. 1961). Quando o quociente "q" não é constante, verifica-se discrepância entre as taxas de mortalidade e recrutamento, que pode levar a mudanças na

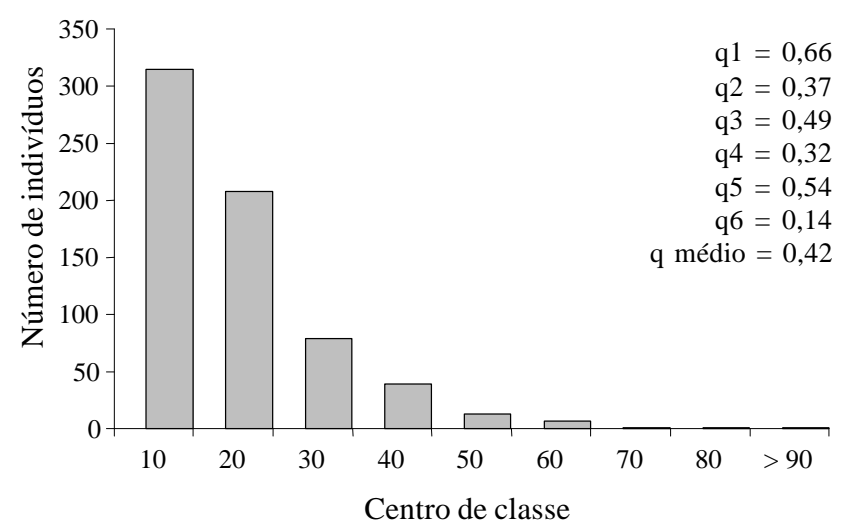

Figura 4. Distribuição das freqüências dos diâmetros em um remanescente de Floresta Estacional Decidual no Município de Monte Alegre, Goiás, Brasil. estrutura da floresta como sugerido por Felfili et al. (1998) para uma Floresta Semidecídua e monodominante em Nova Xavantina, Mato Grosso.

Quanto à distribuição de diâmetro das espécies (Fig. 5), apenas Combretum duarteanum, espécie de porte mediano, apresentou a forma típica de J-invertido, sugerindo capacidade de auto-regeneração e manutenção dos níveis atuais de densidade. Dilodendron bipinnatum e Machaerium aculeatum apresentaram poucos indivíduos na primeira classe, entre 5 e $15 \mathrm{~cm}$ diâmetro, e a partir daí as distribuições seguiram a forma de J-invertido, e portanto, existe a possibilidade de estarem apresentando problemas de recrutamento em períodos mais recentes.

A distribuição das principais espécies de interesse comercial como Myracrodruon urundeuva e Tabebuia impetiginosa reflete as conseqüências da extração, com o desbalanço entre as classes. Myracrodruon urundeuva assim como Tabebuia impetiginosa são usados para madeira de construção e cercamento a partir de cerca de $20 \mathrm{~cm}$ diâmetro e Tabebuia impetiginosa é usada para movelaria. Astronium fraxinifolium também apresenta distribuição com menos indivíduos até $20 \mathrm{~cm}$ diâmetro do que seria esperado no modelo de J-invertido, sugerindo regeneração insuficiente. Esta baixa densidade naquela faixa de diâmetro pode ter sido resultante da retirada de varas para cabos de ferramentas.

Atualmente a floresta não está em fase de exploração e não há evidências desta ter sofrido desmatamento (corte raso), mas há evidência de corte seletivo de espécies de valor comercial pela presença de tocos e pela própria distribuição das espécies. No momento a floresta está se auto-regenerando, mas esperam-se mudanças na estrutura com redução nas 
populações das espécies comerciais. Há que se ressaltar que algumas espécies requerem escala espacial e temporal muito ampla para atingir equilíbrio entre mortalidade e recrutamento (Felfili 1997).

Estes fragmentos de Floresta Estacional Decidual em afloramento de calcário, na região nordeste de Goiás, representam um dos mais importantes remanescentes deste tipo de vegetação florestal dentro do bioma cerrado. A existência, neste remanescente,

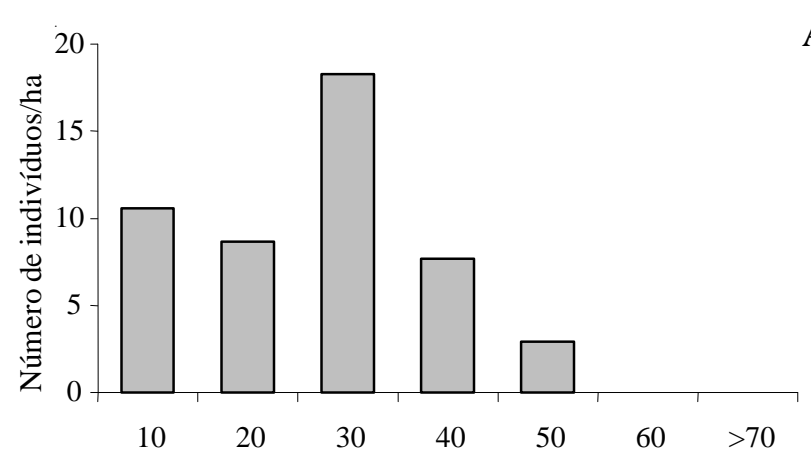

A
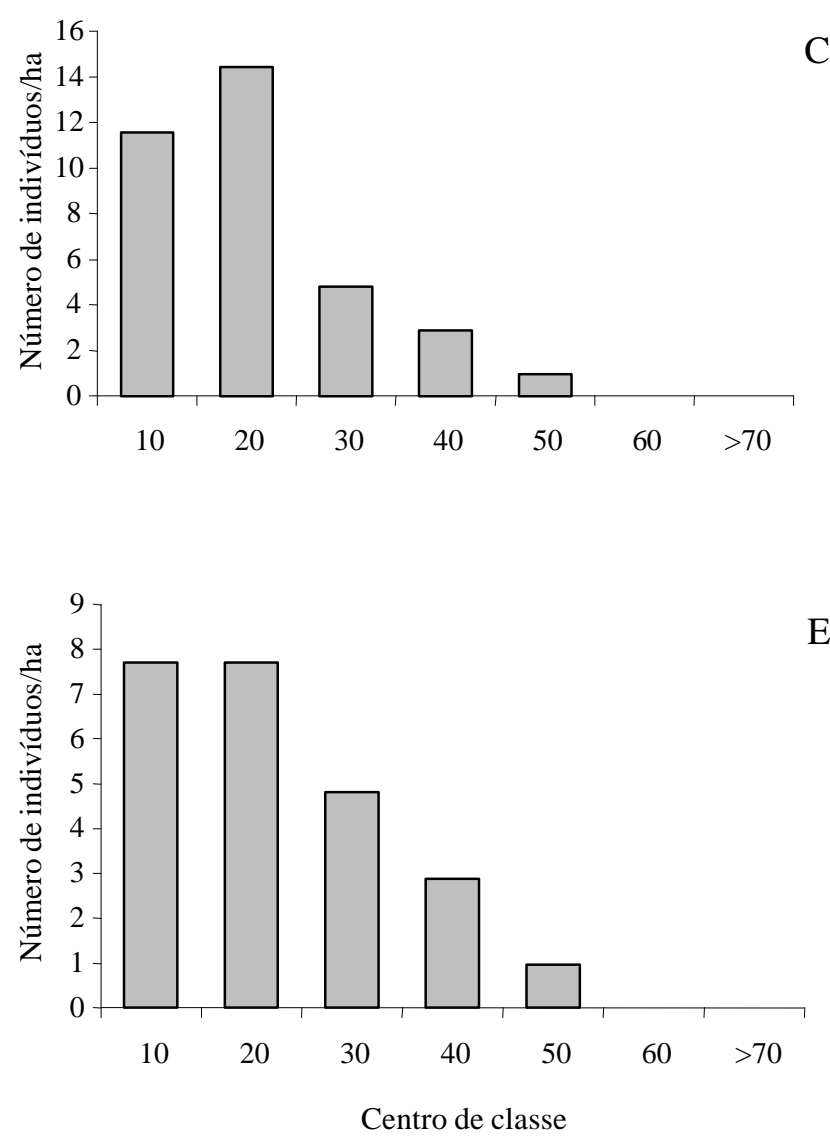

de populações expressivas de espécies arbóreas madeiráveis como Myracrodruon urundeuva (48 ind./ha), Tabebuia roseoalba (42 ind./ha) e Astronium fraxinifolium (21 ind./ha) coloca este local como fonte importante de material vegetal (sementes, pólen, produtos madeiráveis) e deve ser considerado prioritário para a manutenção da diversidade arbórea destas comunidades em escala regional, assim como contemplado nos programas de manejo florestal.
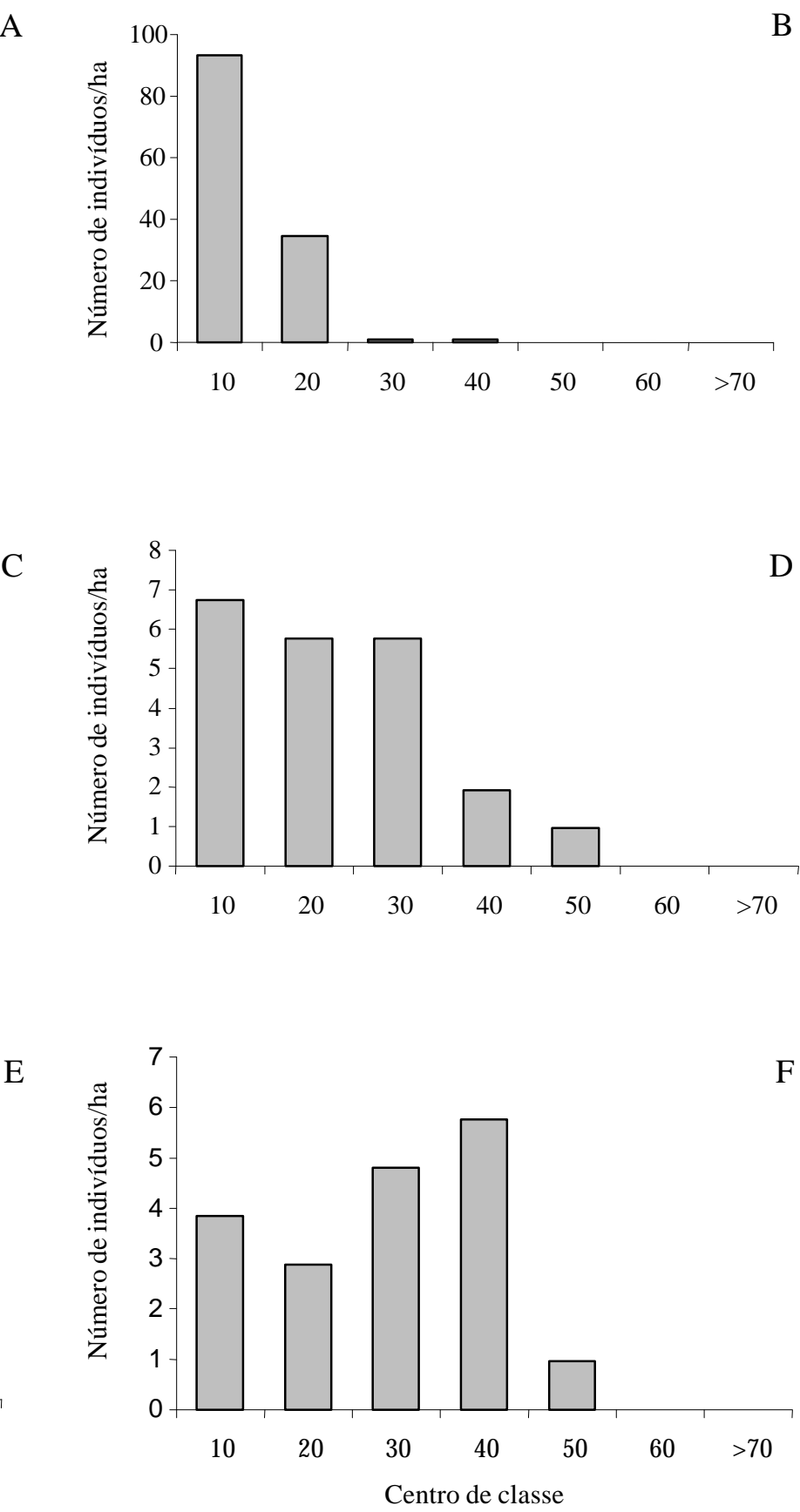

Figura 5. Distribuição de diâmetros das seis principais espécies arbóreas por hectare na Floresta Estacional Decidual em Monte Alegre, Goiás, Brasil. A. Myracrodruon urundeuva. B. Combretum duarteanum. C. Dilodendron bipinnatum. D. Astronium fraxinifolium. E. Machaerium aculeatum. F. Tabebuia impetiginosa. 
Tabela 3. Espécies amostradas por família na Floresta Estacional Decidual em Monte Alegre, Goiás, Brasil.

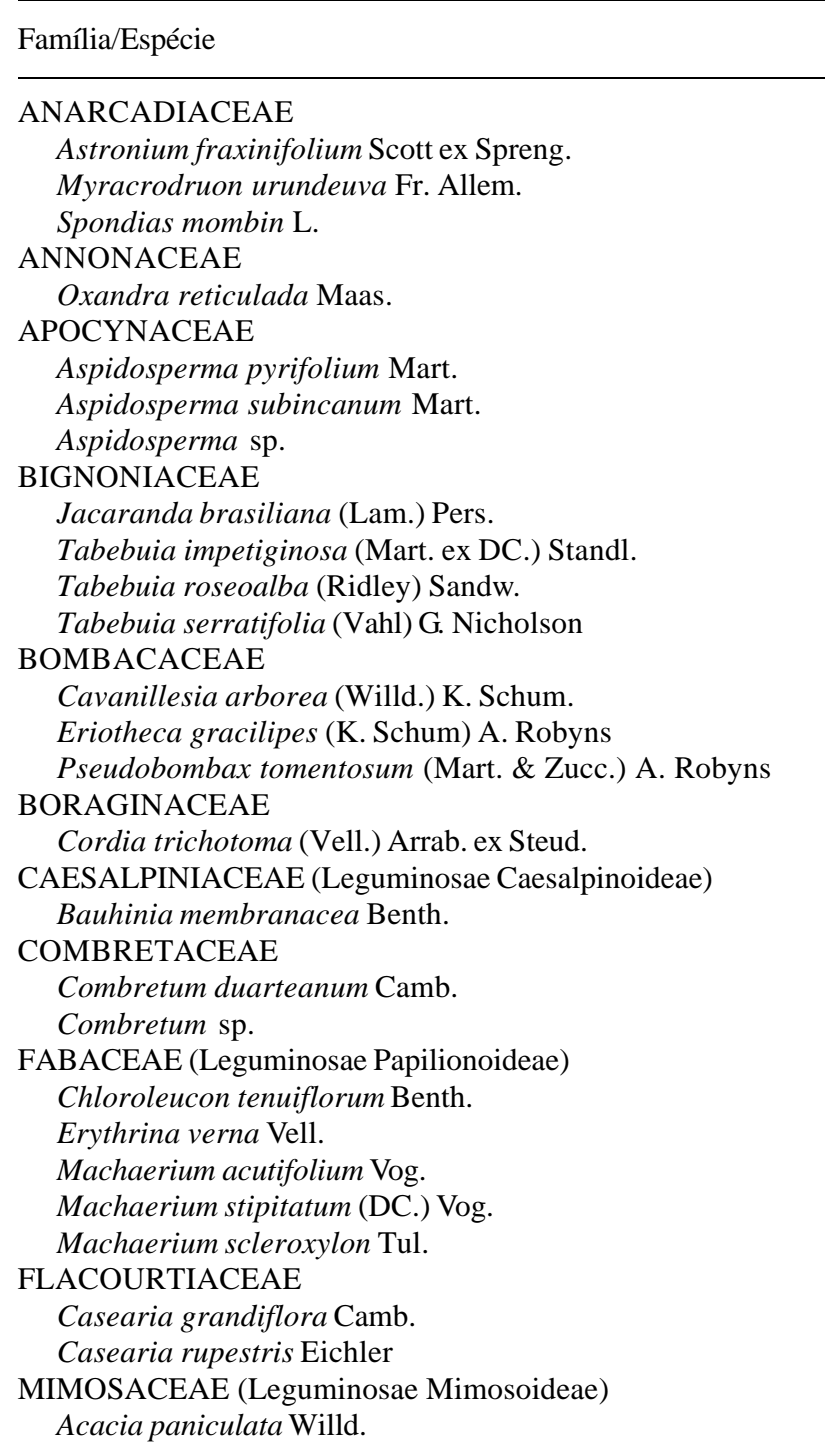

\section{Agradecimentos}

Este trabalho é parte do projeto "Estratégias para a Conservação e Manejo da Biodiversidade em Fragmentos de Florestas Semidecíduas" financiado pelo PROBIO e CNPq. Os autores agradecem ao CNPq/PIBIC e CAPES, pelas bolsas concedidas; ao coordenador geral do projeto, $\mathrm{PhD}$. Aldicir Scariot e sua equipe, pelo apoio administrativo; a Roberta C. Mendonça, Benedito A. Pereira, Christopher W. Fagg e Marina Fonseca, pelo auxílio na determinação de material botânico da região; aos funcionários Edson Cardoso, Newton Rodrigues e José Deassis Alvarenga, pela ajuda na coleta dos dados; aos demais membros da equipe do herbário do IBGE, pela coleta e processamento de material botânico.

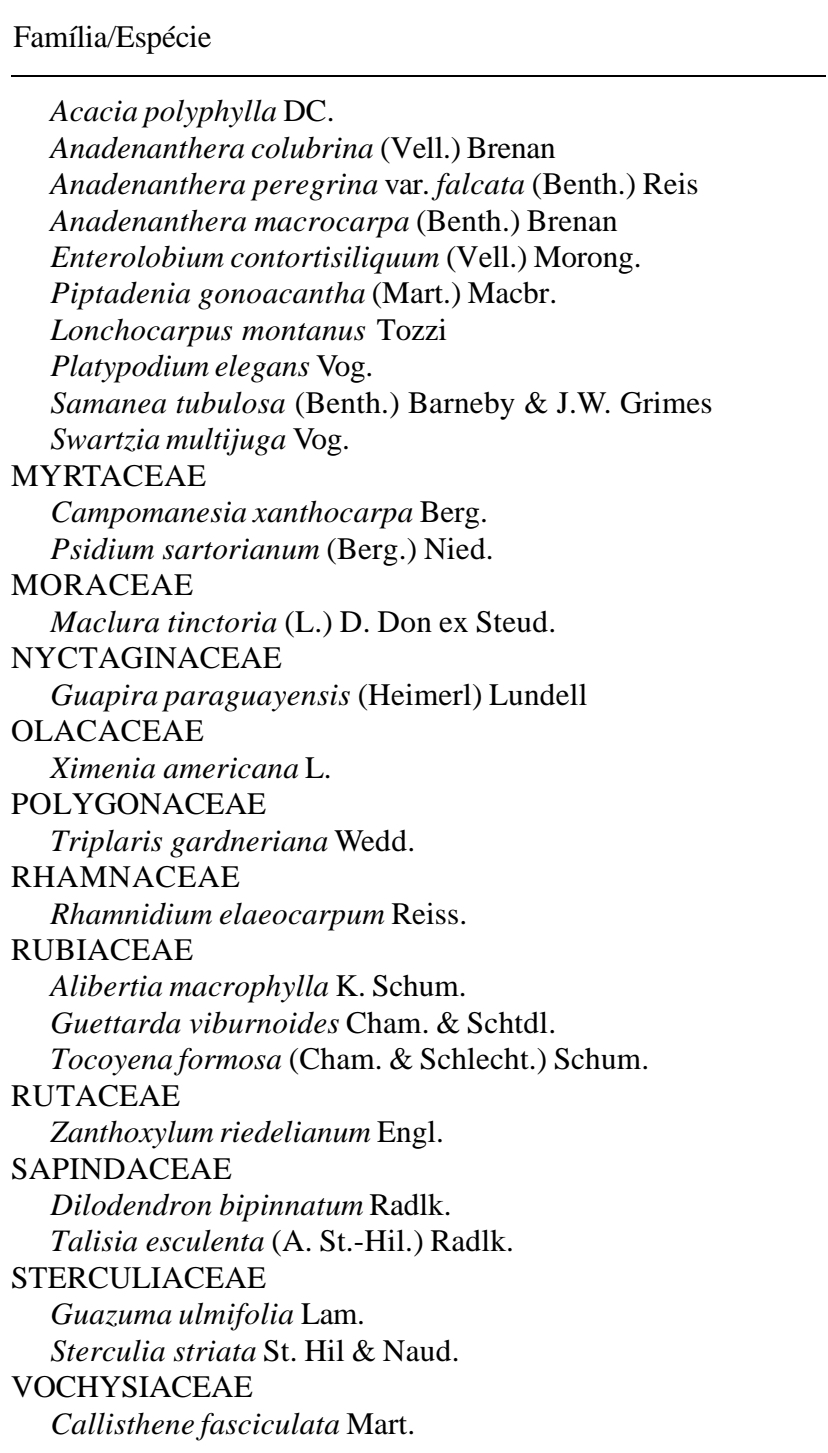

\section{Referências bibliográficas}

Carvalho, J.O.P. 1992. Structure and dynamics of a logged over Brazilian Amazonian rain forest. $\mathrm{PhD}$. Thesis, University of Oxford, Oxford.

Departamento Nacional de Meteorologia. 1992. Normais Climatológicas (1961-1990). Ministério da Agricultura e Reforma Agrária, Brasília.

Felfili, J.M. 1995. Diversity, structure and dynamics of a gallery forest in central Brazil. Vegetatio 117: 1-15.

Felfili, J.M. 1997. Diameter and height distributions in a gallery forest community and some of its main species in central Brazil over a six-year period (1985-1991). Revista Brasileira de Botânica 20: 155-162.

Felfili, J.M.; Silva Junior, M.C.; Nogueira, P.E. 1998. Levantamento da vegetação arbórea na região de Nova Xavantina, MT. Boletim do Herbário Ezechias Paulo Heringer 3: 63-81. 
Felfili, J.M. 2001. As principais fisionomias do Espigão Mestre do São Francisco. Pp. 18- 30. In: J.M. Felfili \& M.C. Silva Junior (orgs.). Biogeografia do bioma cerrado: estudo fitofisionômico da Chapada do Espigão Mestre do São Francisco. Universidade de Brasília, Faculdade de Tecnologia, Departamento de Engenharia Florestal, Brasília.

Felfili, J.M.; Silva Junior, M.C.; Sevilha, A.C.; Rezende, A.V.; Nogueira, P.E.; Walter, B.M.T.; Silva, F.C.C. \& Salgado, M.A. 2001. Fitossociologia da vegetação arbórea. Pp. 35-56. In: J.M. Felfili \& M.C. Silva Junior (orgs.). Biogeografia do bioma cerrado: estudo fitofisionômico da Chapada do Espigão Mestre do São Francisco. Universidade de Brasília, Faculdade de Tecnologia, Departamento de Engenharia Florestal, Brasília.

Felfili, J.M.; Nogueira, P.E; Silva Junior, M.C.; Marimon, B.S.; Delliti, W.B. 2002.Composição florística e fitossociologia do cerrado sentido restrito no município de Àgua Boa, MT. Acta Botanica Brasilica 16: 103-112.

FINATEC. 2001. Inventário Hidrelétrico da Bacia do Rio Paranã. Mapas de vegetação, solos e geologia. Finatec/ Agência Nacional de Energia Elétrica, Brasília.

Finegan, B. 1996. Pathern and process in neotropical secondary rain forests: the first 100 years of sucession. Trends in Ecology and Evolution 11: 119-124.

Gentry, A.H. 1995. Diversity and composition of neotropical dry forests. Pp. 46-194. In: S.H. Bullock; H.A. Mooney \& E. Medina (eds.). Seasonally dry tropical forests. Cambridge University Press, Cambridge.

Hartshorn, G.S. 1980. Neotropical forest dynamics. Biotropica 12: 23-30.

Hubbell, S.P. 1979. Tree dispersion, abundance and diversity in a tropical dry forest. Science 203: 1299-1309.

Hubbell, S.P. \& Foster, R.B. 1986. Biology, change, history and the structure of tropical rain forest tree communities. Pp. 314-329. In: J. Diamond \& T.J. Case (eds.). Community Ecology. Harper and Row: New York.

Hubbell, S.P. \& Foster, R.B. 1987. La estructura espacial en gran escala de un bosque neotropical. Revista de Biologia Tropical 35: 7-22.

Hopkins, B. 1992. Ecological processes at the forest-savanna boundary. Pp. 21-33. In: P.A. Furley; J. Proctor \& J. Ratter (eds.). Nature and dynamics and Forest- savanna boundaries. Chapman Hall, London.

IBGE. 1990. Mapa da vegetação Brasileira. Instituto Brasileiro de Geografia e Estatística.

Lemos, J.R.; Rodal, M.J.N. 2002. Fitossociologia do componente lenhoso de um trecho de vegetação de caatinga no Parque Nacional da Serra da Capivara, Piauí, Brasil. Acta Botanica Brasilica 16: 23-42.

Marimon, B.S.; Felfili, J.M.; Haridassan, M. 2001. Studies in monodominant forests in Eastern Mato Grosso, Brazil: I. A forest of Brosimun rubescens Taub. Edinburg Journal of Botany 58: 123-137.

Martijena, N.E. \& Bullock, S.H. 1994. Monospecific dominance of tropical deciduous forest in Mexico. Journal of Biogeography 21: 63-74.
Martins, F.R. 1991. A estrutura de uma floresta Mesófila. UNICAMP, Campinas.

Medina, E. 1995. Diversity of life forms of higher plants in neotropical dry forests. Pp. 221-242. In: S.H. Bullock; H.A. Mooney \& E. Medina (eds.). Seasonally dry tropical forests. Cambridge University Press, Cambridge.

Meyer, H.A.; Recknagel, A.B.; Stevenson, D.D. \& Bartoo, R.A. 1961. Forest management. Belhaven Press, London.

Miller, P.M. \& Kauffman, J.B. 1998. Effects of Slash and burn agriculture on species abundance and composition of a tropical deciduous forest. Forest Ecology and Management 103: 191-201.

Oliveira-Filho, A.T.; Mello, J.M. \& Scolforo, J.R. 1997. Effects of past disturbance and edges on tree community structure and dynamics within a fragment of tropical semideciduous forest in south-eastern Brazil over a fiveyear period (1987-1992). Plant Ecology 131: 45-66.

Oliveira-Filho, A.T.; Curi, N.; Vilela, E.A. \& Carvalho, D.A. 1998. Effects of canopy gaps, topography and soils on the distribution of woody species in a Central Brazilian deciduous dry forest. Biotropica 30: 362-375.

Pedrali, G. 1997. As florestas Secas sob afloramento de calcário: florística e fisionomia. Bios 5: 81-89.

Pennington, R.T.; Prado, D.E.; Pendry, C.A. 2000. Neotropical seasonally dry forests and Quaternary vegetation changes. Journal of Biogeography 27: 261-273.

Pinard, M.A.; Putz, F.E.; Rumíz, D.; Guzmán, R. \& Jardim, A. 1999. Ecological characterization of tree species for guilding forest management decisions in seasonally dry forests in Lomerío, Bolívia. Forest Ecology and Management 113: 201-213.

Reatto, A.; Correia, J.R.; Spera, S.T. 1998. Solos do bioma cerrado: aspectos pedológicos. Pp. 48-86. In: S.M. Sano \& S.P. Almeida (eds.). Cerrado: ambiente e flora. EMBRAPA - CPAC, Planaltina.

Ribeiro, J.F. \& Walter, B.M.T. 1998. Fitofisionomias do bioma Cerrado. Pp. 89-166. In: S.M. Sano \& S.P. Almeida (eds.). Cerrado: ambiente e flora. EMBRAPA - CPAC, Planaltina.

Rodrigues, L.A. \& Araújo, G.M. 1997. Levantamento florístico de uma mata decídua em Uberlândia, Minas Gerais, Brasil. Acta Botanica Brasilica 11: 229-236.

Sampaio, A.B. 2001. Efeito de borda nas espécies arbóreas de uma Floresta Estacional Decidual no vale do Paranã. UnB, Dissertação de Mestrado, Brasília.

Scariot, A. \& Sevilha, A.C. 2000. Diversidade, estrutura e manejo de florestas deciduais e as estratégias de conservação. Pp. 183-188. In: T.B. Cavalcanti \& B.M.T. Walter [et al.] (orgs.). Tópicos atuais em Botânica. Brasília: Sociedade Botânica do Brasil/Embrapa Recursos Genéticos e Biotecnologia.

Silva Junior, M.C. 1995. Tree communities of the gallery forest of the IBGE Ecological reserve, Federal District, Brazil. PhD. Thesis, University of Edinburg, Edinburg. 
Spiegel, M. P. 1976. Estatística. McGraw-Hill, São Paulo. Sukumar, R.; Suresh, H.S.; Dattajara, H.S.; Joshi, N.V. 1998 Dynamics of a Tropical deciduous forest: population changes (1988 through 1993) in a 50-ha plot at Mudumalai, Southern Índia. Pp. 495-506. In: F. Dallmeier \& J.A. Comiskey (eds.). Forest Biodiversity research, monitoring and modeling. Man and Biosphere Series, v.20. UNESCO/Partenon Publishing Group,Washington DC.
Trejo, I. \& Dirzo, R. 2000. Deforestation of seasonally dry tropical forest: a national and local analysis in Mexico. Biological Conservation 94: 133-142.

Vaccaro, S. 1997. Caracterização fitossociológica de três fases sucessionais de uma Floresta Estacional Decidual, no município de Santa Tereza, RS. Dissertação de Mestrado, Uuniversidade Federal de Santa Maria, Santa Maria. 